\title{
DIGITAL IDENTIFICATION OF THE EMISSION SPECTRUM LINES OF MAGNETRON DISCHARGE
}

\author{
I.A. Afanasieva ${ }^{1}$,S.N. Afanasiev ${ }^{1,2}$, V.V. Bobkov ${ }^{1 *}$, V.V. Gritsyna ${ }^{1}$, D.R. Drozdov ${ }^{1}$, \\ Yu.E. Logachev', A.A. Skrypnyk ${ }^{1}$, D.I. Shevchenko ${ }^{1}$ \\ ${ }^{1}$ V.N. Karazin Kharkiv National University, Kharkiv, Ukraine; \\ ${ }^{2}$ National Science Center "Kharkov Institute of Physics and Technology”, Kharkiv, Ukraine \\ *E-mail:plip@karazin.ua
}

To obtain the qualitative and quantitative characteristics of the discharge plasma spectrum in the Python programming language, a multifunctional interactive GUI-application OSA (Optical Spectrum Analyzed) was created. The application allows you to download a digital image of the optical spectrum, automatically determine the wavelength of the selected spectral line and do elements interpretation.

PACS: 34.50.Dy, 34.50.Fa, 39.30. +W

\section{INTRODUCTION}

Optical emission spectrometry is a widely used and highly informative method for diagnostic of magnetron discharge (MD) plasma [1 - 4]. Using spectrometric methods, it is possible to investigate a number of processes and phenomena occurring in plasma by studying the electromagnetic radiation of plasma particles in an excited state. In particular, by the intensity of the corresponding spectral line, one can judge the population of the excited states of plasma particles; the spatial distribution of the spectral line intensity along a defined direction gives information on the distribution of excited plasma particles along this direction; knowledge of the absolute continuum of plasma radiation gives information about the concentration of plasma electrons and the function of the energy distribution. The ion composition of plasma can be estimated from the ratio of the intensities of the spectral lines of the various plasma components.

Traditionally, the photographic method of radiation registering with photographic materials (film, photographic plates) and analyzing their blackening was used to record plasma radiation [5]. This method of radiation recording and analyzing is very laborious and gives a large experimental error. Nowadays, with the onset of CCD matrices [6], new methods for radiation detecting and analyzing using digital techniques are being developed.

The paper presents the results of obtaining the emission spectrum of the MD by registering it using a CCD

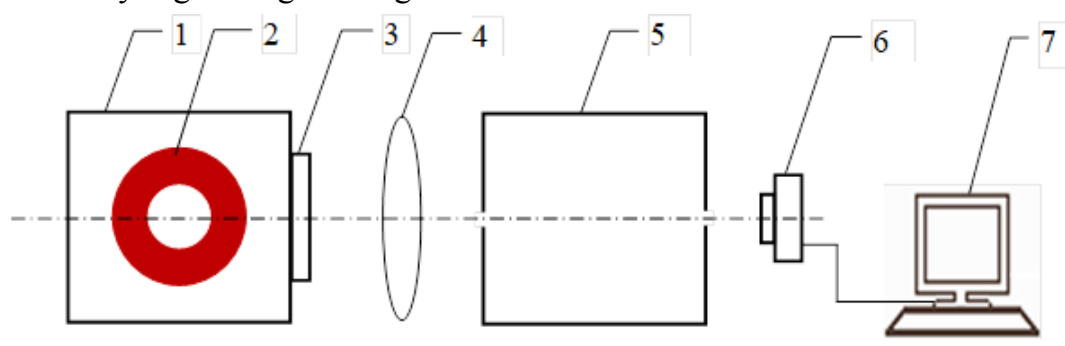

Fig. 1. Block diagram of the experimental setup

The glow spectrum, which was focused on the exit slit of the spectrograph collimator, was recorded with a digital camera (6), and then transmitted via USB to a PC (7). The result of each measurement session was a photograph of the emission spectrum of the plasma area under investigation in *.jpg format, which was then saved in the data bank and allowed further detailed matrices and further analyzing (determining the wavelength of the spectrum and its interpretation) with the created software.

\section{EXPERIMENTAL SETUP}

The block diagram of the experimental setup [7] shown in Fig. 1.

A magnetron sputtering devise (2) (MSD) was placed in a vacuum chamber (1), which acts as the anode. The MSD target was a tungsten disk with a diameter of $20 \mathrm{~mm}$ and a thickness of $0.2 \mathrm{~mm}$. The magnetic field induced by the system of permanent magnets provides the intensity of the tangential component of the magnetic induction of $0.05 \mathrm{~T}$ near the cathode surface. The chamber was pre-evacuated to a pressure of $10^{-2} \mathrm{~Pa}$. Argon was used as a buffer gas, which was supplied into the chamber with the CNA-2 inlet system. The pressure of the working gas changed in the range of $7 \ldots 14 \mathrm{~Pa}$. The light emission of the bright area of the discharge was extracted through the window (3) and was focused by the long-focus lens (4) on the entrance slit of the spectral device (5). In this work, a three-prism glass spectrograph ISP-51 was used, in which the radiation separation into a spectrum in the wavelength range of $400 \ldots 700 \mathrm{~nm}$. Along the height (h) of the focal plane, the radiation of the discharge area (L) is projected, they are connected by the relation $\mathrm{L}=\mathrm{kh}$, where $\mathrm{k}$ is the magnification in the lens-spectrometer system. study of the emission spectra for different operating parameters of the MD.

Fig. 2 shows a part of the emission spectrum of particles excited in a magnetron discharge with a tungsten target. The magnetron parameters are: discharge current $\mathrm{I}_{\mathrm{d}}=70 \mathrm{~mA}$, discharge voltage $\mathrm{U}_{\mathrm{d}}=350 \mathrm{~V}$, argon pressure $\mathrm{p}_{\mathrm{Ar}}=10 \mathrm{~Pa}$. 
As can be seen from the figure, the spectrum of the area of bright glow of a magnetron discharge is a set of spectral lines of certain wavelength. Information on the wavelengths of the spectral lines that present in the optical spectrum allows us to determine the qualitative composition of the plasma of the magnetron discharge.
The main step in processing a digital image is the determination of the wavelength of a particular line and its interpretation, that is, the determination of belonging the analyzed line to a certain chemical element in a certain charge and energy state [8].

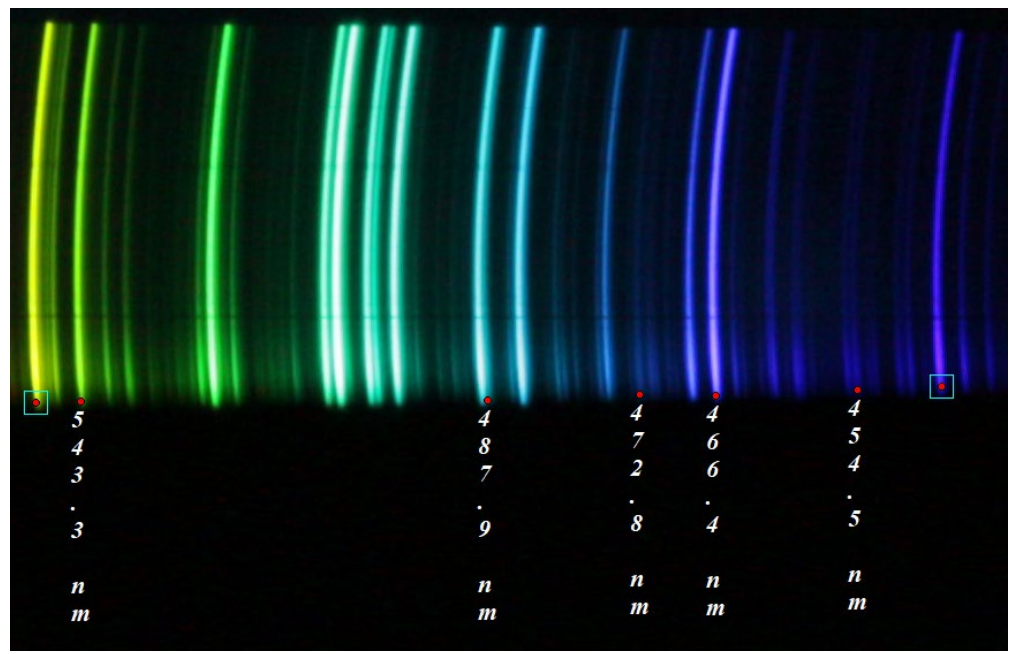

Fig. 2. Part of the emission spectrum of the ionization zone of the magnetron discharge

\section{METHODS OF DIGITAL OPTICAL IMAGE PROCESSING}

An OSA application (Optical Spectrum Analyzed) [9] has been developed for processing digital images of MD plasma spectra. It allows obtaining information on the state of a emitting particle directly with a computer without using any additional measuring devices. This application was created in the Python language [10] using the PIL module (a special multifunctional library for working with images, which allows both to perform the necessary manipulations with the image and to access each individual pixel).

The OSA application has a scenario cycle of scanning events generated by user actions such as keyboard input, keystrokes, or coursor movement. For each potential event, a function is assigned that will be called when this event occurs. For each function, it is possible to create a specific graphic component (widget), which can be placed on the application canvas.

Methods of digital image processing imply working with raster images, the smallest unit of which is a pixel, characterized by intensity (color depth). From a mathematical point of view, an image is a three-dimensional matrix $f[x, y]$, where $x$ and $y$ is an integer describing the number of the column or row of the matrix where this element with the intensity $\mathrm{I}[\mathrm{x}, \mathrm{y}]$ is located. The intensity range is from 0 (black) to 255 (white). In the OSA application an algorithm for conversion a digital image into such a three-dimensional array of numbers is realized. Any other data can be obtained only as a result of applying a number of procedures for processing and analyzing the obtaining set of numbers. The results of mathematical processing are visualized in digital photography, which allows online monitoring of the process of obtaining physical information.

\subsection{DETERMINATION OF THE WAVELENGTH OF THE SPECTRAL LINE}

At the first stage of spectrum image processing, the OSA application binds the measuring coordinate system (pixel) to the experimental one. In the corresponding widgets (Fig. 3, inset at the top) the wavelengths for the two reference spectral lines are entered, and in the image the position of the coordinates of these lines in pixels are recorded (see Fig. 2, closed circles in square frames).

Binding is done if wavelengths of reference lines are known. Otherwise, it is necessary to get the reference spectrum (of neon, mercury or hydrogen lamps), for which the interpretation in $\lambda$ lines is known.

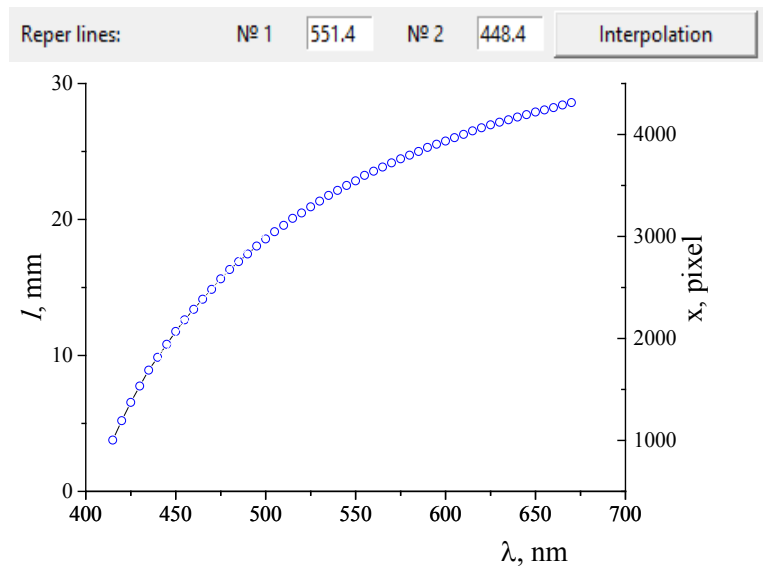

Fig. 3. Calibration of the pixel coordinate system with the experimental. Above - the OSA application widgets, below - a graduated curve of the digital

frame $f(\lambda, l)$ for conversion to the pixel scale $f(\lambda, x)$

For the ISP-51 spectrograph at separating into a spectrum nonlinear dispersion is characteristic [5]; this implies the presence of a nonlinear calibration scale (see Fig. 3, the graph) connecting the values of the $l$ line position to the wavelength $\lambda$ in $\mathrm{nm}$. The ordinate axis on 
the right shows the scale of the values of the digital matrix $x$ in pixels. In the available wavelength range for the reference lines on the abscissa scale by interpolation the corresponding values on the ordinate scale (left) in $\mathrm{mm}$ are found. This allows you to enter the pixel-mm scaling factor and, using inverse interpolation, automatically determine the wavelength $\lambda$ for an arbitrary line on the digital image in the pixel coordinate system.

In Fig. 2 closed circles indicate the position of the line under study, and vertically arranged figures indicate the wavelength $\lambda$ of the line. A multiple measurement of the wavelengths of several spectral lines was made and the statistical error $\delta \lambda$ was obtained when determining the wavelength using the OSA application. The error $\delta \lambda$ on average is in the range from 0.075 to $0.2 \mathrm{~nm}$, depending on the distance of the measured line from the first reference line.

Fig. 2 shows, that the characteristic of the spectral line is its high intensity (at least, the excess over the background intensity $\mathrm{I}^{\text {fon }}$ ). The experimental value $I^{\text {fon }}=\left(\sum_{i=1}^{n} I_{i}\right) / n$, where $I_{i}-$ the pixel intensities in the range between the reference points, $\mathrm{n}-$ the number of pixels.

\subsection{DETERMINATION OF THE ELEMENTAL COMPOSITION OF THE SPECTRUM}

At the second stage, the search for the most probable elements occurs, excited atoms or ions of which are present in the discharge plasma. The database of spectral lines [11] contains a pattern set $\left(\mathrm{N}_{\text {elem }}\right)$ of the most intense lines for each element, for which the charge state of an element atom is indicated ( $\mathrm{I}$ is the atomic spectrum, II is the ion spectrum), line intensity $\left(\mathrm{I}_{\lambda}\right)$ and excitation energy $\left(\mathrm{E}^{*}, \mathrm{eV}\right)$. As a rule, the number of $\mathrm{N}_{\text {elem }}$ for different elements is different.

Using the interpolation method, the value of the wavelength $\lambda^{\text {sh }}$ of the pattern line (in $\mathrm{nm}$ ) was plotted on a digital image. The $\mathrm{I}^{\text {sh }}$ intensity value was also automatically determined. Since there is an error in determining the position of a line in a digital image, in addition to the intensity of a specific point, the intensity of the contour around this point was determined. The intensity of the contour $I^{\text {cntr }}$ for the matrix $3 \times 3$ was defined as the Sobel operator as follows: $\mathrm{I}^{\mathrm{cntr}}=\left(\mathrm{I}_{\mathrm{x}}{ }^{2}+\mathrm{I}_{\mathrm{y}}{ }^{2}\right)^{0.5}$, where $\mathrm{I}_{\mathrm{x}}=\sum_{1}^{3} \mathrm{I}_{\mathrm{x}}^{\text {up }}-\sum_{1}^{3} \mathrm{I}_{\mathrm{x}}^{\text {down }}$, and $\mathrm{I}_{\mathrm{y}}=\sum_{1}^{3} \mathrm{I}_{\mathrm{y}}^{\text {left }}-\sum_{1}^{3} \mathrm{I}_{\mathrm{y}}^{\text {right }}$;
$\mathrm{I}_{\mathrm{x}}{ }^{\text {up }}$ and $\mathrm{I}_{\mathrm{x}}{ }^{\text {down }}$ - the top and bottom rows of the matrix $3 \times 3, \mathrm{I}_{\mathrm{y}}{ }^{\text {left }}$ and $\mathrm{I}_{\mathrm{y}}$ right are the left and right columns of the matrix. If $\mathrm{I}^{\text {sh }}>\mathrm{I}^{\text {fon }}$ and $\mathrm{I}^{\text {cntr }} \sim \mathrm{I}^{\text {fon }}$, then this line is considered to be present in the spectrum.

Sequential search, in the automatic mode, for each element determines the probability of its presence in the spectrum $\eta^{\text {elem }}=\mathrm{N}^{\text {exist }} / \mathrm{N}^{\text {elem }}$. The number of $\mathrm{N}^{\text {exist }}$ lines is defined as the sum of patterned lines that satisfy the condition of presence in the spectrum. If a large number of intense spectral lines of a certain element coincide with a number of lines present in the MD spectrum, the corresponding chemical element can be considered present in the spectrum with very high reliability. For further analysis in a separate widget you can pointed out the limit value of the probability $\eta^{\lim }$ (in the interval $0 \ldots 1$ ), which allows you to select from all elements only those with $\eta^{\text {elem }}>\eta^{\text {lim }}$.

\subsection{INTERPRETATION OF SPECTRAL LINES}

An algorithm has been developed that allows for each experimentally determined wavelength of a separate line $\lambda$ to associate the most probable value from the table of spectral lines. The data for the elements with $\eta^{\text {elem }}>\eta^{\text {lim }}$ are taken into consideration. For each spectral line there are 3 comparison parameters, on the basis of which the spectral lines are interpreted: directly the wavelength of the line, the intensity of this line and its excitation energy.

By a simple comparative search, the interval of values is fixed in the table, in which one of the experimental values of $\lambda$ gets. A boundary criterion is introduced for the reliability of tabulated experimentally determined values of the wavelength $\lambda$, determined by the measurement error $\delta \lambda$. If the boundary values are in the confidence range, then from the two limit values, the one with the maximum intensity value $\mathrm{I}_{\lambda}$ is selected. In case of equality in this parameter, the third comparison element is used - the excitation energy $E^{*}$. The advantage is given to the variant with a smaller value of the excitation energy. It should be noted that the lines of various elements can be blended, therefore experimental lines, in which a variant of several elements (n) is possible in the boundary range, have an interpretative probability proportional to $1 / \mathrm{n}$.

Interpretation of spectral lines

\begin{tabular}{|c|c|c|c|c|c|}
\hline Data & \multicolumn{5}{|c|}{$\lambda, \mathrm{nm}$} \\
\hline experiment & 543.3 & 487.9 & 472.8 & 466.4 & 454.5 \\
\hline $\begin{array}{c}\text { interpreta- } \\
\text { tion }\end{array}$ & $543.5 \mathrm{~W} \mathrm{I}$ & $\begin{array}{c}487.9 \mathrm{Ar} \mathrm{I} \\
487.8 \mathrm{~W} \mathrm{I}\end{array}$ & $472.7 \mathrm{Ar} \mathrm{I}$ & $466.3 \mathrm{~W} \mathrm{I}$ & $454.5 \mathrm{Ar}$ II \\
\hline
\end{tabular}

The table shows the interpretation of a number of lines defined in Fig. 2 in the experiment with a tungsten target and argon as a buffer gas.

\section{CONCLUSIONS}

To solve actual problems associated both with the development of the theory of a magnetron discharge, and with the expansion of the field of its practical appli- cation, a digital technique for processing the emission spectra of the discharge plasma has been proposed. A graphic OSA application has been created that allows to obtain qualitative and quantitative characteristics (wavelength, interpretation and intensity) of the plasma spectral line of a magnetron discharge. A procedure has been created to gain access to the numerical matrix of a digital image of the emission spectrum of excited particles 
and to make the conversion from the pixel coordinate system of a photo to the experiment coordinate system. The algorithms to determine the wavelength of a specific spectral line has been developed. Analysis by wavelength allows identifying the charge and energy state of the excited particles, which makes it possible with a high probability to determine the elemental composition of the discharge plasma.

The created OSA application, for the convenience of experimental material processing, has a number of functionalities, such as the simultaneous analysis of several spectral lines and the recording of each processing session into an external information file. The undoubted advantage of the created application is the open code, which allows making changes to it, based on the solution of a specific task.

The proposed technique makes it possible to significantly speed up the process of obtaining physical information and improve the accuracy in determining the parameters of the spectrum. The digitally obtained photographs of the emission spectra of the reference objects, supplemented by the data processed by the OSA software application, allow you to create a data bank that includes both atlases of the emission spectra of various elements in electronic form and the quantitative parameters of these spectra.

\section{REFERENCES}

1. U.A. Zheleznov, V.U. Homich. Eksperimental'nyj metod passivnoj opticheskoj diagnostiki plazmy // Prikladnaja fizika. 2011, № 3, p. 60-66 (in Russian).

2. M. Novotne, J. Bulнш, P. Pokorne, et al. Optical emission and mass spectroscopy of plasma processes in reactive DC pulsed magnetron sputtering of alu- minium oxide // Journal of Optoelectronics and Advanced Materials. 2010, v. 12(3), p. 697-700.

3. V.E. Fortov. Enciklopedija nizkotemperaturnoj plazmy. Vvodnyj tom II, Kniga II. M.: «Nauka», 2000, 633 p. (in Russian).

4. V.N. Ochkin. Spektroskopija nizkotemperaturnoj plazmy. M.: «Fizmatlit», 2006, 472 p. (in Russian).

5. V.I. Malyshev. Vvedenie v jeksperimental'nuju spektroskopiju. M.: «Nauka», 1979, 480 p. (in Russian).

6. V. Deckert, W. Kiefer. Scanning multichannel technique for improved spectrochemical measurements with a CCD camera and its application to raman spectroscopy // Applied spectroscopy. 1992, v. 46(2), p. 322-328.

7. I.A. Afanasieva, V.V. Bobkov, V.V. Gritsyna, et al. On excited particle formation in crossed ExH fields // Vacuum. 2018, v. 149, p. 124-128. (in Russian).

8. A.A. Babushkin, P.A. Bazhulin, F.A. Korolev, et al. Metody spektral'nogo analiza. M.: Izd. Mosk. Univ., 1962, 507 p. (in Russian).

9. I.A. Afanasieva, S.N. Afanasiev, N.A. Azarenkov, et al. Digital processing of optical emission spectra of magnetron sputtering plasma system // Problems of Atomic Science and Technology. Series "Physics of Radiation Effects and Radiation Materials Science". 2019, №2(120), p. 164-167.

10. Mark Lutz. Learning Python, 5th Edition Packages. «O'Reilly Media», 2013, 1648 p.

11. A.N. Zajdel', V.K. Prokof'ev, S.M. Rajskij, et al. Tablicy spektral'nyh linij. M.: «Nauka», 1977, 800 p. (in Russian).

Article received 18.06.2019

\section{ЦИФРОВАЯ ИДЕНТИФИКАЦИЯ ЛИНИЙ ЭМИССИОННОГО СПЕКТРА МАГНЕТРОННОГО РАЗРЯДА}

И.А. Афанасьева, С.Н. Афанасьев, В.В. Бобков, В.В. Грицына, Д.Р. Дроздов, Ю.Е. Логачев, А.А. Скрипник, Д.И. Шевченко

Для получения качественных и количественных характеристик спектра плазмы разряда на языке программирования Руthon создано многофункциональное диалоговое GUI-приложение OSA (Optical Spectrum Analyzed). Приложение позволяет загрузить цифровое изображение оптического спектра, в автоматическом режиме определить длину волны выбранной спектральной линии и выполнить элементную интерпретацию.

\section{ЦИФРОВА ІДЕНТИФІКАЦІЯ ЛІНІЙ ЕМІСІЙНОГО СПЕКТРА МАГНЕТРОННОГО РОЗРЯДУ}

\section{І.О. Афанасьєва, С.М. Афанасьєб, В.В. Бобков, В.В. Грицина, Д.Р. Дроздов, Ю.С. Логачов,} А.О. Скрипник, Д.І. Шевченко

Для отримання якісних і кількісних характеристик спектра плазми розряду на мові програмування Python створено багатофункціональний діалоговий GUI-додаток OSA (Optical Spectrum Analyzed). Додаток дозволяє завантажити цифрове зображення оптичного спектра, в автоматичному режимі визначити довжину хвилі обраної спектральної лінії і виконати елементну інтерпретацію. 